\title{
Ex post assessment methods of climate forecast impacts
}

\author{
Siwa Msangi, Mark W. Rosegrant*, Liangzhi You \\ International Food Policy Research Institute, 2033 K Street NW, Washington, DC 20006, USA
}

\begin{abstract}
While a considerable body of literature has grown around the ex ante assessment of the value of climate forecast information, relatively little has been applied to ex post analyses. Using the literature that assesses the impact of agricultural research and extension as a starting point, our paper suggests advancements in survey design, data collection, econometric methodology and project evaluation that can improve ex post impact assessment of climate forecast information. We also emphasize the need to better integrate economic theory with empirical methodology, so as to account for behavioral dynamics and the presence of rigidities and fixities facing economic agents and food production systems. Through these types of advances in theoretical and empirical modeling, researchers will be better equipped to conduct ex post impact assessment and more accurately measure the value of the climate forecast information reaching the agricultural producer.
\end{abstract}

KEY WORDS: Economic valuation - Econometric methods - Ex post assessment $\cdot$ Climate forecast Resale or republication not permitted without written consent of the publisher

\section{INTRODUCTION}

In recognition of the growing importance of global climate change and its impacts on environmentally dependent economic systems such as agriculture, the economic literature has increasingly addressed the implications for climate forecast information, and the value of climate forecasts to the decision maker. Starting from the theoretical foundations of decision-making under uncertainty, this growing body of literature has mainly relied on a perspective that looks at the value of information ex ante of the realization of the actual climate event. Such examples (Byerlee \& Anderson 1969, Mjelde et al. 1988, Mjelde \& Hill 1999) often use Bayesian decision theory to show how beliefs held prior to the forecast can change with the dissemination of information, and how that can, in turn, influence optimal behavior. The imputation of value to that information can then be done through a comparison of the benefits of decisions (e.g. crop mix, input use) that are accrued in the presence or absence of forecast information.

This type of ex ante approach, while informative to the researcher who wants to better understand how information influences decision-making and behavior in an uncertain environment, can only offer a limited valuation of what forecast information is actually worth, as it is largely normative in nature. In contrast to this type of approach, an ex post analysis would base its valuation on the observed actions of the economic agent and how he responded to the realized environmental shock or climate outcome. Examples of this kind of analysis are far fewer than those employing an ex ante perspective, due, in part, to the more challenging empirical questions surrounding its valuation.

In this paper, the term 'climate forecast' refers to a seasonal forecast provided with a given lead-time to the predicted event. The forecast itself might have some uncertainty embedded in its predictions, but will nonetheless serve to narrow the band of uncertainty that the intended user of the information has. We envision such a user to be either a farm-level agent making an agricultural production decision; although a policylevel decision-maker might also benefit, the focus of the paper is mostly on the decisions of the former, rather than the latter.

The distinction we make between ex ante and ex post types of analysis can be illustrated with the help of the timeline in Fig. 1: 


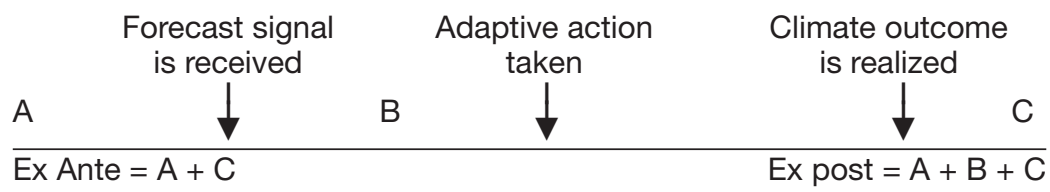

Fig. 1. Timeline of information, adaptation and climate outcomes to highlight differences between ex ante and ex post types of analyses

The present study is arranged as follows. Following a section that gives an overview of traditional impact assessment methodology, we discuss the challenges that are inherent to conducting ex post valuations of climate information. The subsequent section looks at several promising examples

In this timeline, point $\mathrm{A}$ represents the decision maker's beliefs about climate before receiving the forecast information, and point B is where his beliefs have now been updated with forecast data, and some degree of adaptive action is being taken in response to the new information. Point $\mathrm{C}$, which can be a few days, months or even years after the climate event, is the point at which all information has been received, and all outcomes realized. An ex ante analysis of forecast value would compare the actions that the decision maker would take if he were to proceed from A directly to $\mathrm{C}$, without taking any adaptive action at point $B$, and calculate the value imputed from the differences between the simulated net benefits. The main focus of such an analysis is on how the forecast information affects the pre-outcome decision strategy of the agent, and the decision maker's actions and response to the climate information must be simulated or projected in some way. This kind of simulated outcome might differ quite significantly from what would actually be observed at point $\mathrm{C}$ if the adaptive actions at point $B$ had been undertaken, which is often a criticism of ex ante types of analyses.

In an ex post analysis, however, the researcher observes the actions of the decision maker at point $\mathrm{C}$ (Fig. 1), by which point adaptive actions in response to the forecast information have been undertaken and the climate outcome has been realized. In this case, the real net benefits are also observed as a result of the decision maker's pre-outcome adaptation and post-outcome actions, and not just simulated. In this way, an ex post analysis is not simply interested in how climate information affects the beliefs of the decision maker, but also in how his actions reflect the use of that improved information, in the face of the actual climate event.

Even in an ex post analysis, the value of the forecast is still inferred from a comparison of the realized net benefits of the individual decision maker, at the farm-level, when he acts both with and without (improved) forecast information. Counterfactual arguments such as this pose a hypothetical which supposes the opposite of what really transpired (e.g. 'what would have happened if Caesar hadn't crossed the Rubicon?'). In the context of the present study, the 'no information' counterfactual hypothesizes behavior in the absence of climate information actually received, and is not as straightforward to consider as it would be in the ex ante case. This empirical challenge will be discussed further in Section 3 . from the literature that demonstrate advancements in empirical methodology, and a final section concludes with recommendations for further research.

\section{APPLICATIONS TO AGRICULTURE RESEARCH}

Since there are few studies that assess the ex post impact of seasonal climate forecasting (Mjelde et al. 1988, Luseno et al. 2003, Lybbert et al. 2003), we drew from the economic literature to gain insight into how impact evaluation methodology may be applied to forecast information. In particular, research experience from the study of farm-level technology adoption can be directly drawn upon when considering the valuation of climate forecast information. The examples which fall most readily to hand are those used in the evaluation of agricultural research investments, and their impact on productivity, revenues and long-term growth. Seasonal climate forecast information, like agricultural research, adds incrementally to the stock of useful knowledge that contributes to agricultural production, through adaptation of technologies, improved productive inputs and new cultivation practices. Such general issues in impact assessment as scale, attribution, adoption, choice of case studies and time lags are common to both agricultural research evaluation and climate forecast assessment. Most importantly, when doing an ex post evaluation of the impacts of agricultural research investment, one is also taking into account the adaptation of behavior, which is embedded into the observed data. The same challenge of introducing the counterfactual of 'no research' also presents itself when considering agricultural research investments.

There are 2 broad approaches to estimating the impact of agricultural research and development (henceforth R\&D) that are of relevance to our discussion of ex post valuation of climate forecast information. The first is the econometric approach that attributes productivity changes directly to research investments. The second is the economic surplus method that builds benefits from the bottom up, based upon estimated productivity changes at the field level and adoption rates for each technology. This is quantified in impact studies by estimating the economic benefits to both producers and consumers due to the 
particular agricultural research activities, and by computing a rate of return to research investments.

The econometric approach may provide a way of addressing the 'no information' counterfactual, and could provide insight into how to address it within the context of climate forecast information. However, it requires large amounts of data which are not usually available to the researchers who carry out impact assessment studies, as would likely be the case for researchers studying ex post valuation of climate forecast information. Therefore, in practice, the economic surplus approach has been much more widely applied (Maredia et al. 2000). Alston et al. (1995) offer an excellent and comprehensive reference on the theory and practice of economic evaluation of research. The following sub-section discusses these 2 approaches, in order to illuminate how they might be applied towards the ex post valuation of climate forecast information.

\subsection{Econometric measurement of the effects of research investments}

In the context of agricultural research investments, econometrically based empirical approaches attribute changes in output, profit, or costs directly to past investments in research and extension through analysis of observed data. The methodology used in an econometric study can vary from one that looks directly at the physical quantities of input and output (a 'primal' approach, using a production function), or one that looks at the relationship in terms of costs and prices (a 'dual' approach which uses a cost function). Additional approaches utilize index-based measures of productivity to measure the improvement over time resulting from research investment (a 'factor productivity' approach).

These approaches could be applied to the ex post valuation of climate forecast information in a way that tries to directly relate the 'stock' of climate forecast information provided over time to the improvements in performance measured at the farm-level. This could be in terms of reduced costs from climate-related damage to agricultural production, which is facilitated by better forecast information, or enhanced productivity over time, as a result of better timing of critical cultivation activities or the adoption of more sophisticated farming practices which make use of the new or improved climate forecast information. In this context, the measurement of the 'stock' of knowledge might be more challenging than that of agricultural research investment, which can be measured in dollar amounts. Undoubtedly, the challenge of determining the 'lag' over which information results in improved outcomes would be an issue, just as it is for agricultural research investments, although it is likely that it would not be nearly as long as the 2 to 3 decades implied in the work of Alston et al. (1995).

Many of the technical issues on refinements to econometric methods that are discussed in the literature (e.g. choice of functional form, or the specification of the length and shape of the time lag) would also apply to the ex post valuation of climate forecast information. However, the main constraint to the wider application of econometrically based approaches is the availability and quality of data. To address these problems, researchers have turned to the use of crosssectional, time-series data (panel data), which have become increasingly available to them (e.g. Huang \& Rozelle 1995, Ali \& Byerlee 1999, Lindert 2001).

The availability of such data could also be useful to the valuation of climate forecast information, if a broad enough cross-section is obtained, such that the variation in forecast information availability is adequately captured. By so doing, the counterfactual of 'no information' can be statistically controlled for in the estimation procedure itself, allowing the effect of new or improved climate forecast information to be evaluated ex post. In such an approach, the adaptations of farmers in response to the forecast information is also captured in the observed data, and should be accounted for in the valuation of forecast information. However, more behavior-specific factors, such as the degree of risk-aversion or far-sightedness in the farmer's perspective, would not be adequately captured in this kind of approach. For this, a more structurally based empirical approach would be required, such that these behavioral characteristics could be modeled and taken into account in the valuation process. This will be discussed at greater length in Section 3, in the context of structural estimation procedures.

\subsection{Economic surplus method}

The economic surplus method introduced by Griliches (1958) has been the most popular and fruitful approach to the assessment of agricultural R\&D impacts. 'Surplus' refers to the gross benefits that the producer receives from production or the consumer from consumption, beyond the costs of either production or purchase. In essence, this method seeks to attribute changes in both producer and consumer welfare to production improvements or cost reductions in agriculture. This approach, in contrast to the econometrically based one described previously, depends more heavily on the specification of the underlying behavioral parameters of the economic agents - namely the producer and consumers. Given its economy-wide approach, however, the level of analysis is carried out at a fairly aggregate level, which may make its application to the 
ex post valuation of forecast information more challenging. The following brief discussion of this approach illustrates why this might be so.

An economic approach to evaluating $R \& D$ begins with the basic commodity market model of research benefits depicted in Fig. 2. In this figure, $S_{0}$ represents the supply function before a research-induced technical change, and $D$ represents the demand function. The initial price and quantity are $P_{0}$ and $Q_{0}$, respectively. Suppose research generates yield-increasing or input-saving technologies. These effects can be expressed as a per unit reduction in production costs, $K$, that are modeled as a parallel shift down in the supply function to $S_{1}$. This research-induced supply shift leads to an increase in production and consumption to $Q_{1}\left(\Delta Q=Q_{1}-Q_{0}\right)$, and the market price falls to $P_{1}$ (by $\left.\Delta P=P_{0}-P_{1}\right)$. Consumers are better off because $\mathrm{R} \& \mathrm{D}$ enables them to consume more of the commodity at a lower price.

Although they receive a lower price per unit, producers who adopt the new technology are better off, too, because their unit costs have fallen by an amount, $K$ per unit, that is more than the fall in price. The consumer 'surplus' measure of the consumer benefit is equal to area $P_{0} a b P_{1}$, i.e. rectangle $P_{0} a e P_{1}\left(=Q_{0} \times \Delta P\right)$ plus triangle abe. The producer surplus measure of the producer gain is equal to area $P_{1} b c d$ in Fig. 2, i.e. rectangle $P_{1}$ ecd $\left(=Q_{0} \times[K-\Delta P]\right)$ plus triangle bce. Total benefits are obtained as the sum of producer and consumer benefits. As an approximation, the cost saving

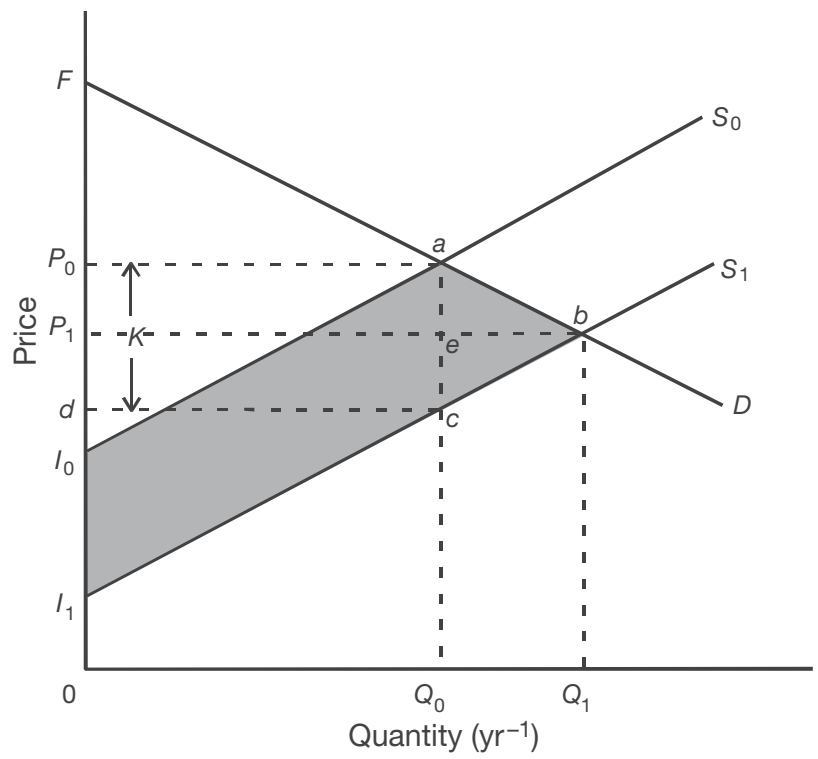

Fig. 2. Basic economic surplus model in a closed economy. $S_{0}$ : supply function before a research-induced technical change, $D$ : demand function, $P_{0}$ : initial price, $Q_{0}$ : quantity, $K$ : per unit reduction in production costs with yield-increasing or inputsaving technologies, modeled as a parallel shift down in the supply function to $S_{1}$. Lower case letters label important points on the graph per unit multiplied by the initial quantity, $K Q_{0}$, is often used. Using the estimated economic surplus together with research costs, we could calculate either the net present value or internal rate of return. Whether or not these changes result in actual benefits or losses to the producers or consumers in the market depends on the relative slope of the supply and demand curves, which in turn rely upon the relative magnitude of the behavioral parameters (elasticities). Therefore positive gains or losses cannot be assigned a priori, but must be evaluated explicitly.

The economic surplus approach requires information on values of production and consumption of the commodity market, the effects of research (measured through comparisons of yield increases and unit costs of production or maintenance both with and without research), adoption rates, research and adoption lags, cost of agricultural R\&D (and extension), and the appropriate discount rate for converting benefits and costs into the present values. The key behavioral parameters that are critical determinants of the resulting gains or losses in 'surplus' are the price elasticities of demand and supply. An 'elasticity' is a dimensionless number which describes the percentage change in demand or supply that occurs in response to a percentage change in the price of a produced or consumed commodity, and the magnitude and nature of the supply (or demand) shifts determine the relative benefits that accrue to both producers and consumers. These parameters capture an element of behavioral response that the traditional econometric approach would miss, although it relates strictly to behavioral response with respect to price, and not any other factor.

This kind of 'price-only' response may not be totally representative of individuals' actual response to climate forecast information, and also may not capture other behavioral preferences with respect to e.g. risk or uncertainty. To explicitly address the case of stochastic outcomes, one would have to adopt a 'Monte Carlo' approach, statistically sampling from possible productivity outcomes in order to generate an ensemble of market-level gains and losses that could generate a distribution of realizable effects. Furthermore, these behavioral elasticities represent a fairly aggregate level of market response that is somewhat removed from the adaptive actions of a farmer who is responding to climate forecast information. However, as before, this framework could be applied to quantify how aggregate market-level benefits might change if farm-level adaptations to better-forecast information lead to reduced supply shocks or reduced costs and damages from climatic events. In order for such an approach to be ex post, however, we would require that the behavioral parameters used to calculate the economy-wide benefits and costs reflect the level of adaptation that has 
already occurred. In contrast to the econometric approach, the counterfactual of 'no information' would also be difficult to construct and succinctly capture in the price-response behavioral parameters.

To economists looking at benefits of cost-reducing or productivity-enhancing investments in practice, the limited data requirements and the explicit theoretically grounded framework make the surplus-based approach more appealing than the econometric approach; however, the converse might be true in the case of ex post evaluation of forecast information. Many of the shortcomings in both of these methods are also shared by other methodological approaches that have been applied to the ex post valuation of forecast information, and the next section will describe these challenges in more detail.

\section{EX POST VALUATION OF CLIMATE INFORMATION}

The task of measuring the impact of either agricultural research or climate forecasting is both complex and challenging, and there are both advantages and disadvantages to applying the methods discussed to the valuation of climate information. The empirical experience gained in applying agricultural research evaluation methods to deal with general issues in impact assessment, such as scale (project, program, institution or the whole system), attribution (proper accounting for costs and benefits), selection bias (random sampling or 'cherry-picking' the best cases), could also provide valuable lessons for assessing the impact of climate forecast information.
There are a number of issues that face the analyst when assessing climate forecasting value. As with any other type of analysis, the latest theoretical advances and empirical tools are used, along with the best possible data. But in order to properly design the anaytical framework, the resarcher must consider the length of the time horizon (short-term vs. long-term valuation) and the degree to which the climate information has been processed. While the researcher is never completely free from uncertainty in the specification of the problem, there is a need to identify the assumptions that are embedded in the analytical framework, particularly in the case of model-based approaches.

The strengths and challenges embodied in structurally based and reduced-form approaches (Table 1) will be elaborated upon further in the discussion that follows, and serve as a focal point for the reader. The remainder of this section will elaborate on the specific kinds of challenges that arise when applying various types of empirical approaches to the ex post valuation of forecast information.

\subsection{Behavioral response in valuation}

While economists have developed useful and readily applicable tools to determine the economic value of environmental amenities and attributes belonging to other consumer goods, the application of these methods to the valuation of climate information ex post of the realized climate outcomes has proved challenging. The primary challenge lies in the fact that ex post valuation of climate information requires the measurement of its implicit value through observed behavior of

Table 1. Comparison of structurally based and reduced-form approaches

\begin{tabular}{|c|c|c|}
\hline Approach & Advantages and strengths & Disadvantages and challenges \\
\hline \multirow[t]{4}{*}{ Structural } & $\begin{array}{l}\text { Ability to directly incorporate risk attitudes and } \\
\text { other behavioral preferences }\end{array}$ & $\begin{array}{l}\text { Requires assumptions on the part of the researcher to } \\
\text { capture structural relationships not measurable with data }\end{array}$ \\
\hline & $\begin{array}{l}\text { Ability to show explicit causal linkages between } \\
\text { actions and drivers }\end{array}$ & $\begin{array}{l}\text { Complex nature of structural models can make it hard to } \\
\text { isolate confounding factors }\end{array}$ \\
\hline & $\begin{array}{l}\text { Ability to explicitly handle uncertainty in } \\
\text { forecasts and actions }\end{array}$ & \multirow{2}{*}{$\begin{array}{l}\text { Counterfactuals may be hard to evaluate in ex post } \\
\text { analyses, as adaptation is built into the structural } \\
\text { estimation of the model }\end{array}$} \\
\hline & Adaptive behavior can be modeled directly & \\
\hline \multirow[t]{5}{*}{$\begin{array}{l}\text { Reduced- } \\
\text { form }\end{array}$} & $\begin{array}{l}\text { Can explicitly control for and isolate } \\
\text { confounding environmental factors }\end{array}$ & \multirow{3}{*}{$\begin{array}{l}\text { Heavily reliant upon data quality and availability. Some } \\
\text { assumptions might be needed for certain types of data } \\
\text { (i.e. perfect market assumption for land prices) } \\
\text { Incorporating risk and uncertainty is difficult }\end{array}$} \\
\hline & Entirely based on data with a minimal & \\
\hline & assumptions on the part of the researcher & \\
\hline & $\begin{array}{l}\text { Relatively simple to formulate, implement } \\
\text { and interpret }\end{array}$ & \multirow[t]{2}{*}{$\begin{array}{l}\text { Causal linkages could be hidden and unobservable in } \\
\text { data }\end{array}$} \\
\hline & $\begin{array}{l}\text { Counterfactual can be assessed ex post } \\
\text { with adequate cross-sectional observations } \\
\text { of 'with' and 'without' cases }\end{array}$ & \\
\hline
\end{tabular}


economic agents, and not through the revelation of directly stated values or through the simulation of 'prescriptive' models that describe behavior ex ante of the realization of the climate event.

The imputation of value from observed behavior requires a structurally based understanding of the underlying processes driving the actions of the economic agent, and sufficient information to allow the researcher to make a distinction between those dimensions of behavior that are driven by climate information and those which are determined by other (potentially confounding) factors. The measurement of information value ex post would then be done by comparing the agent's realized net benefits with or without improved forecast information, either through direct behavioral simulation of a structural model or through calculations based on reduced-form relationships that are derived from observed data. 'Reduced-form' describes a simplified (usually equation-based) relationship between influencing factors and outcomes, which hides the detailed linkages of causality that a more explicit structural model would reveal. A demand curve is, in essence, a reduced-form relationship that can also be reproduced with an explicit model of consumer consumption that maximizes benefit subject to a household budget.

A key consideration here would be the stochastic nature of the predictions that are made in climate forecasts, as well as the stochastic nature of the climate outcomes, themselves. A reduced-form relationship would not be able to take into account the uncertainty in the information or how the agent responds to that uncertainty. A more structurally based model which models the agent's beliefs and how they change with information (even 'noisy' information signals) would be able to account for this uncertainly more explicitly, and even capture the agent's attitudes toward uncertainty and risk. These types of behavioral responses are best handled within the context of a structurally-based analytical framework, rather than a reduced-form relationship that might only capture the average conditions and responses to them.

A key difference between an ex ante and ex post analysis of climate information value can be best characterized by drawing a distinction between those analyses which use behavioral models that prescribe optimal behavior based on the researchers choice of model and information structure, and those analyses which use more descriptive models incorporating structural features that describe the relationship between the decision-maker's behavioral preferences or characteristics, the information that he receives, and the actions that he takes, as a result of prior climate information and in reaction to the realization of the actual climate event. Stewart (1997) describes the steps taken in a 'descriptive' analysis (Fig. 3).

The sequence of analysis described here includes a validation stage which represents a crucial difference between this approach to behavioral modeling, and one in which the researcher's understanding and assumptions on behavior and user preferences are the overwhelming drivers of the analysis. The biggest challenge lies in Step 4, which requires the empirical analysis to correctly attribute the influence of information on the observed actions of the economic agent receiving it. In order to do this, the empirical methodology must be robust enough to eliminate potentially confounding factors that could otherwise wrongly attribute observed behavior to the climate information received, when it is actually being driven by another latent influence or constraint.

\subsection{Agent-specific valuation}

The methods employed by economists in measuring the value of consumable goods (or their attributes), are heavily focused on statistical econometric analyses that use the observed choices of the consumer to directly 'reveal' the value of the consumed good, or which impute the value of the good through the behavior of the consumer in another economic market that is assumed to be linked closely to the actual economic good of interest. These approaches can be described, respectively, as 'direct' and 'indirect' valuation methods, and have an illustrious history of use in the field of environmental economics, as described in Freeman (1993).

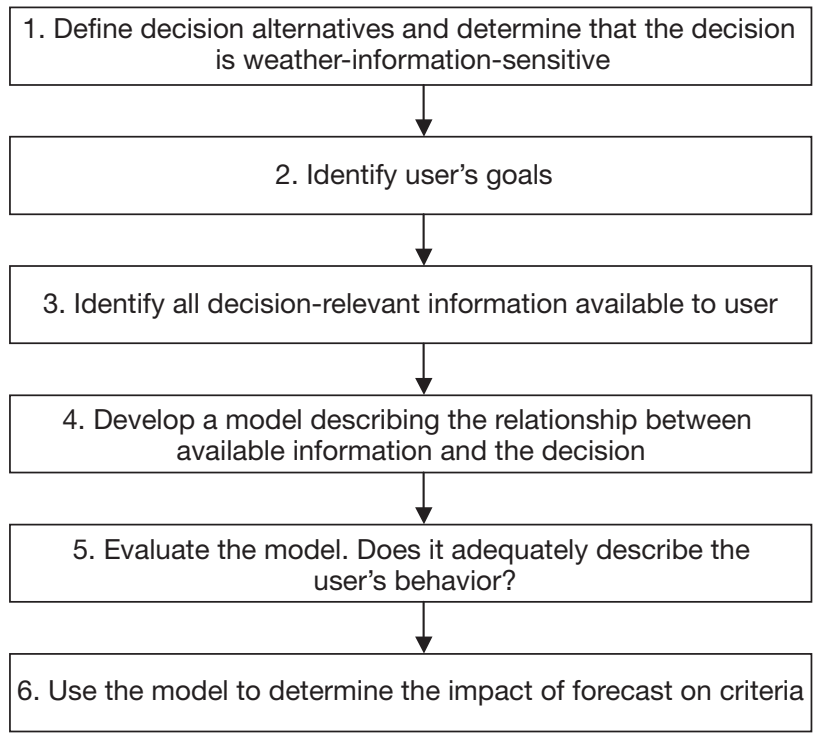

Fig. 3. Methodological approach to descriptive modeling (from Stewart 1997) 
What makes these types of methods ex ante or ex post in nature, however, is the degree to which the valuation of information is based on directly observed behavior, as opposed to hypothetical responses or the researcher's own conjecture. Table 2 describes how various types of forecast valuation could be classified with respect to direct, indirect, ex ante or ex post methods.

For instance, an ex ante approach to a 'direct' valuation of climate information would rely on questioning the consumer directly about the value of the forecast, in the absence of the actual experience of receiving the information, whereas an ex post analysis would require the value to be revealed by observing the consumer's response to the information that is provided, within the context of a real weather event. In either case, the valuation is directly tied to the content of the climate forecast.

Indirect valuation methods, on the other hand, require the researcher to infer the value of the economic good (namely the forecast information), from the economic agent's behavior towards another good or activity that is indirectly connected with it. The relationship between the forecast information and the indirectly related good or activity must be established conceptually within the mind of the researcher, such that the economic decision-maker's behavior with respect to one good implies a valuation of the other. To use a simple recreational example, an indirect method would value the pristine nature of a lake based on the observed activity at a nearby boat rental shop, under the assumption that a clean lake is complementary with boating and canoeing activities. While there could be ex ante methods of performing indirect valuation of climate forecast information, the most readily understandable applications would be more ex post in nature, such as tying the way in which people buy umbrellas to their perceptions of weather outcomes.

In the environmental economics literature, the most commonly used indirect valuation approach is the use of 'hedonic' models to impute the value of a good through observed behavior in a complementary market, the classic example being that of air quality and how it influences the decisions of buyers in the housing market (Ridker 1967, Ridker \& Henning 1967). The term 'hedonic' arises because the researcher is relying on the theory of utility (or satisfaction) to relate the decision maker's value of one good through his behavior to another related good. Other applications to land value and environmental quality have been numerous, starting from those of Strotz (1968), Lind (1973), Freeman (1974), Pines \& Weiss (1976) and Polinsky \& Shavell (1976).

The underlying assumptions of these type of models, however, require not only that there is complementarity between the true economic good of interest (soil or water quality) and the market good (farm acreage value), but it also assumes that a 'perfect' market for farmland exists, such that the observed prices in that market fully and correctly reflect consumers' behavior and preferences, and that these price signals are not contaminated with imperfection in the market structure. The comparatively well-functioning agricultural land markets allow researchers to use hedonic methods to infer adaptations on the part of farmers to changing climate conditions (e.g. Schlenker et al. 2005).

The challenge of applying this kind of methodology to the valuation of climate information lies in both the limited range of situations in which these assumptions would be applicable (e.g. most developing countries have agricultural land markets that are 'thin' and which function too poorly to provide plausibly reliable price signals) and, more fundamentally, in the fact that climate information has a different relationship to consumer behavior than actual climate, which would be a more reasonable driver of land purchases or the choice of crops that are grown on it.

An econometrically based analysis which relies on direct revelation of value through observed behavior would also face challenges when applied to the study of climate information, as the analytical framework must be rich enough in structure (and sufficiently supplied with data) to be able to control for confounding influences on behavior that could bias the measured influence of climate information on observed behavior. The example of television climate information suggested by Macauley (1997), in which the value of

Table 2. Correspondence between valuation methods and modeled behavior

\begin{tabular}{|lll|}
\hline Valuation & Observed behavior (ex post) & Hypothetical behavior (ex ante) \\
\hline Direct & $\begin{array}{l}\text { Experiments that measure response to better } \\
\text { information in a laboratory } \\
\text { Observed behavior under improved information } \\
\text { from collected data }\end{array}$ & $\begin{array}{l}\text { Questions on willingness-to-pay for better forecasts } \\
\text { Simulated behavior under improved information }\end{array}$ \\
Indirect & $\begin{array}{l}\text { Hedonic values generated by actual behavior } \\
\text { within a related market that can be tied to forecast } \\
\text { information }\end{array}$ & $\begin{array}{l}\text { Contingent ranking of attributes that can be indirectly } \\
\text { related to forecast }\end{array}$ \\
\hline
\end{tabular}


climate information disseminated through the television could be imputed from observing the value of the airtime that the TV stations allocate to such announcements, embodies such an empirical challenge.

The primary assumption, in this example, is that the time that a station would allocate to a climate announcement reflects the 'patience level' of the viewer, which is capitalized into the value of airtime that is charged to advertisements on a particular network channel or station. Not only is the measurement of consumer impatience subject to challenge, but the absence of any link between the climate information and how it affects consumer behavior ex post of the realized climate shock also becomes evident. As Stern \& Easterling (1999) point out, there is no reliable link between expenditures on forecasting and their actual value, due to the fact that the agents might not have a clear understanding of what they are really buying.

A more rigorous approach would require a choice model to be constructed for the television viewer, such that the observed actions of the consumer (on choice of dress or mode of transport) could be directly linked to the forecast information provided through the television, and that other confounding factors that could influence choice, such as the price of transport or the non-climaterelated aesthetic considerations of clothing choice, could be properly controlled for. Arguably, personal characteristics that are indicative of attitudes towards risk could also be captured in such a framework. Simulations of choices can then be run with this constructed model, to determine the value-added of climate information, in terms of enabling the consumer to make better choices than s/he would in the absence of it.

The obvious burden of data required to statistically control for such confounding factors would be the same if it were applied to an agricultural context. The actions of the farmer, in terms of planting choice or timing of harvesting or weeding would also have to be directly linked to climate information, and the abilities and resources of the farmer would have to be controlled for, so that the ability of the farmer to respond to information is controlled for when evaluating its value. In the context of a structurally explicit optimization framework, this could be measured through the observed shadow values (i.e. measures of the marginal change in benefit - or cost — that would result from a constraint being 'relaxed' slightly) on those constraints.

\subsection{Adaptation and structural relationships in valuation}

Antle (1996) pointed out that econometric models of adaptation to climate change value that rely on aggregate measures of land value and net benefits fail to make the connection between climatic influences and the optimizing behavior of farmers responding to them. While the Ricardian-type of analyses (after the economist David Ricardo; relying on the imputed values of land) of Mendelsohn et al.(1996) do take into account the adaptation of farmers to climate shocks, they omit the explicit linkages between climate and agricultural production, and are at risk of overlooking important structural changes that could influence adaptation behavior. Therefore, using this type of model to infer the value of a perfect forecast, as is done by Easterling \& Mendelsohn (1999), might result in biased estimates, as the true value of the information might be masked by other factors that impinge on farmers' adaptive ability to respond to better information (Stern \& Easterling 1999). It is precisely this aspect of ex post climate forecast valuation-correctly representing the limits and constraints on behavior that influence observed response to information - that causes researchers to prefer a more structural approach to evaluating the influence of information on behavioral response, rather than relying on purely reduced-form, statistically derived relationships.

Provencher (1997) drew a useful comparison between the application of structural versus reducedform approaches to the characterization of decision processes, within the context of dynamic, optimal stopping problems. While his example was not applied to climate information, insight can be gained nonetheless from his critique of the reduced form approach, as it relates to the Lucas Critique (i.e. Lucas 1976) of reduced-form behavioral models, and how they might overlook the influence of a changing policy environment. Provencher (1997) advocates the employment of a more explicit structural model that can better describe how environmental changes influence observed behavior, and applies it to the case of timber harvesting, where the decision-maker responds to price signals in a stochastic economic environment. In comparing reduced-form and structural models, Stern \& Easterling (1999) also note that coping variables, representing farmers' adaptive strategies, should be treated as endogenous in an analysis of forecast value.

Perhaps the best example of the structural approach is Fafchamps' (1993) example of West African farming, where he assesses the timing of labor decisions and how these are influenced by the physical environment, and how farmers are observed to behave when subjected to stochastic environmental shocks, such as drought and flood. In order to carry out his analysis, he constructs a behavioral model of farming with structural estimation techniques, such that he is able to incorporate the labor constraints of the farm household directly into the model. By doing so, he is able to capture how the farmer actually responds to climate out- 
comes in the presence of these constraints, and to represent the trade-offs between earning household income and enjoying leisure explicitly. This is in contrast with the somewhat prescriptive structural approach adopted by Fox et al. (1999) in their valuation of climate forecast information with the example of alfalfa hay farming in Ontario, Canada. Despite their use of crop simulation results to represent fodder growth response to environmental changes more realistically, their specification of producer behavior imposes a mean-variance utility type on the farmer, whose parameters are varied through sensitivity analysis, rather than estimated from data. This difference distinguishes the more descriptive approach used by Fafchamps (1993), and others who use longitudinal data (i.e. measurements on the same experimental subjects over time) to examine how environmental variations affect the decisions of farmers who might face resource constraints or missing markets for insurance, and must adapt by buying or selling assets (Stern \& Easterling 1999).

These types of structural behavioral analyses represent the state-of-the-art in behavioral modeling, and have the best chance of overcoming the confounding influences that could bias the valuation of climate information in ex post analyses. Structural estimation also allows the researcher to investigate the preferences of the decision-maker and to examine the role that risk-aversion plays in their actions. This added richness, however, must be balanced with the extra computational costs inherent in these types of models, as is described in the classic exposition of this method by Rust (1987). This fact often leads researchers to limit the number of parameters to be estimated with structural estimation methods, so as to reduce the computational burden (Stern \& Easterling 1999). However, the conceptual superiority of this type of modeling approach remains clear, and will become more evident in the literature as computational efficiency and speed of estimation algorithms improve.

Whether a farmer (or other agent) failed to adequately respond to climate information because of constraints he faces in farming skill, in on-farm resources, or because of the quality of the information itself, is a question that can only be answered by adopting a 'descriptive' modeling approach that can explicitly incorporate these types of constraints. Such constraints could also be related to household-level structural factors, or even constraints relating to institutions or interactions with other agents. The approach of multi-agent systems analysis (Wooldridge 2002) or other types of agent-based modeling approaches could be useful in exploring these issues, as well.

In the following section, we describe some studies that show promise in overcoming some of the inherent difficulties in the estimation of climate information value.

\section{TRENDS IN THE LITERATURE}

With increasing technological advances in climate forecasting, and a growing volume of data, the number of studies that attempt to evaluate this information has also grown rapidly. The preponderance of evidence from the empirical literature suggests that society would benefit from the use of improved climate forecast, and the value of this information is scenariospecific (Mjelde et al. 1998). While there are few ex post studies using the econometric approach, the majority of those that have done so have used the economic surplus method to measure the value of climate information. Solow et al. (1998) estimate net benefit from the use of ENSO-based climate information to range between US\$240 and US\$320 million $\mathrm{yr}^{-1}$ for the US agriculture sector alone in the last few decades. Adams et al. (1995) examined the benefits of improved information on the forecast of El Nino-Southern Oscillation (ENSO) events to farmers in the southeastern USA. In that study, the authors considered precipitation, in particular, and its effect on crop yield, in order to measure the enhanced benefits that would result from improved accuracy in forecast information. They then compared these benefits to the additional gains that would accrue to the farmers in the presence of perfect forecast information. Adams et al. (1995) even made a distinction between the value of improved (but imperfect) forecast information, and the value that arises from behaving with the benefit of perfect foresight. The value of perfect information is up to US\$265 million $\mathrm{yr}^{-1}$ for the entire US, compared to US\$130 million $\mathrm{yr}^{-1}$ with imperfect information. Their work is more specific to the actual value of improved forecast information than an earlier study by Bradford \& Kelajian (1978) which looked at the benefit-to-cost ratio of reducing sampling error in government-collected crop and livestock statistics, or in the study by Hayami \& Peterson (1972), which considered a point estimate of benefit losses resulting from less-than-perfect forecast information, in terms of its impact on inventory adjustments of wheat. The application of the surplus method by Freebairn (1976) used similar methodology to Adams et al. (1995), but dealt with forecasts of commodity price information, rather than climate information. More advanced theoretical and empirical treatments of forecast information valuation, such as that of Antonovitz \& Roe (1984) which evaluated the surplus gains within a rational expectations framework, are relatively few in number and tend to be more ex ante in their approach, than the ex post studies cited above.

Some particularly promising research has emerged in recent literature that has the potential for pushing forward the state-of-the-art in ex post valuation of 
forecast information. One study (Luseno et al. 2003) applies econometric analysis to the observed behavior of pastoralists, and also combines some analysis of response to directly asked questions, to elicit an overall picture of how rural pastoralists actually value and use the forecast information that they have. Others follow more along the lines of experimental economics, and observe agent response within a controlled setting in order to better isolate the impact that information has on the action of decision makers. Both of these approaches have their own merits, and potential pitfalls, and we will spend the remainder of this section discussing them in some detail, so as to highlight the aspects that hold the greatest promise of advancing the current methods used for the ex post impact assessment of climate information.

Climatic variability is especially pronounced and important in the dryland and semi-dryland regions in Africa. Pastoralists depend on extensive livestock systems that are highly sensitive to disease and climateinduced spatio-temporal variability in forage and water availability. Climate forecasting information, in particular seasonal forecasting, is valuable to these pastoralists. A recent study (Luseno et al. 2003) describes pastoralists in the arid and semi-arid lands of southern Ethiopia and northern Kenya and the degree of access they have to both external and indigenous climate forecast information. The study, which covers a fairly large region (about $200000 \mathrm{~km}^{2}$ ) before, during and after the 2001 long rains season (spring rainy season), also describes their level of confidence in this information and the extent to which they make use of it. Those authors used both quantitative survey data and qualitative methods to assess the value of climate forecast information to these pastoralists. Their methodology could be summarized in the following 7 crucial questions that need to be addressed in order to assess the impact of climate forecast information on any population of intended beneficiaries, including African pastoralists. (1) Do the intended climate forecast end-users, in this case the uneducated pastoralists, have the ability to adapt their traditional approach to forecasting in order to make use of this new kind of information? (2) What sort of prior beliefs or information do the prospective users hold with respect to climate patterns? (3) Who actually receives external forecasts? (4) What level of confidence do the recipients have in external climate forecasts? (5) Is the external forecast different from the pre-existing, indigenous forecast? (6) How does the receipt of and confidence in external climate forecasts change the way in which users take preventive or adaptive actions to mitigate the impacts of climate outcomes? (7) How do the pastoralists' updated beliefs on climate affect their decisions, and what are the welfare consequences? This case study concludes that seasonal climate forecast information has little impact on pastoralists. However, it shows the complexity involved in the valuation of climate forecasts, and the principles it identifies are relevant to future studies.

Another paper on livestock operations, by Jochec et al. (2001), estimated the value of forecasts by simulating the forage stocking decisions with an integrated ecological-economic model, as well as with information from focus group discussions. While the forecast values were generated from a constructed simulation model, the decision rules that drive the model behavior were elicited from the focus group participants, so that adjustments to these rules could be made in the face of improved forecast information. In a somewhat different formulation, Lybbert et al. (2003) attempted econometric estimation of the process by which farmers updated their beliefs; a Bayesian decision framework was used to explain the factors that influence the perception of climate information among pastoralists. While employing a novel approach, those authors did not actually estimate any values associated with the improvement of the pastoralists' beliefs, and thus their study cannot be directly compared to other ex post assessments in the present study.

Another promising trend in the literature, which might serve to further the state-of-the-art in climate forecast valuation, is the use of experimental results. With the aim of determining the level of cost-savings that could be realized by an agribusiness firm receiving forecast information, Sonka et al. (1988) carried out an empirical analysis using controlled decision experiments to test the responses of subjects who were provided with varying degrees of climate information. They focused on the agribusiness sector, in order to investigate how climate information could be used to make more effective decisions within a specific business setting. Their experiment involved a significant degree of participation on the part of the respondents, so that real behavior could be observed and subjected to econometric analysis by the researchers.

In Sonka et al.'s (1998) experimental simulations, the decision makers were asked to allocate alternative seed varieties among a number of planting sites, so that the amount produced could meet an expected level of sales and also replenish stock carryovers to a desired level. Any shortfalls in production, as a result of simulated stochastic weather outcomes, would result in a loss of sales, and a certain penalty against the firm's profits. The level of forecast information provided to the subjects would then affect their perception of expected yields and prevailing planting conditions, and thereby cause them to make adjustments in their planting decisions and production plans. By generating sequences of weather types over a $10 \mathrm{yr}$ period, the 
researcher is then able to examine the responses of decision makers over different year types, to carry out a statistical analysis of their responses to different climate forecasts, and to evaluate the effect of forecast improvements on profits.

A valid critique of this kind of approach is that the type of behavior involved in this type of experiments may not necessarily reflect the actual behavior that would be observed in an uncontrolled, real-world setting. Nonetheless, observing how experimental subjects respond to information in this type of setting might still capture many dimensions of real behavior, as the subjects would actually be responding directly to the information being provided, and their other personal characteristics could be directly controlled for in any econometric analysis of the results. In the absence of fortuitous and clear-cut natural experiments that would allow a researcher to isolate the effect of improved climate forecast information in a randomly collected sample of data, these experimental methods might provide the next-best thing for examining the effect of improved information on user decisions. As techniques for designing economic experiments become more refined and sophisticated, some of these shortcomings in 'reality' may be reduced as simulations get closer and closer to the kinds of situations that decision-makers would actually face in a real climate scenario.

\section{CONCLUSIONS}

In this paper, we have reviewed some 'traditional' methods of ex post impact assessment in agricultural $\mathrm{R} \& \mathrm{D}$ and have pointed out the possibilities and challenges of applying these economic valuation methods to the assessment of climate information value. While it may not be possible to treat climate information as the type of economic good that has measurable consumer surplus value, the cost-reducing effects of better climate information might lend itself to the economic assessment methods that make use of cost functions in agricultural production. In particular, the ability to take into account attitudes towards risk by the user of climate forecast information will depend very much upon the methodological approach used in carrying out ex post valuation.

As was discussed in the context of agricultural technology adoption, the determination of 'lags' in the response to climate forecast information should also be taken into account when attempting to value such information ex post. The application of econometric reduced-form methods allows for the explicit testing and specifications of such lags in the empirical framework, which would otherwise be difficult if one had to rely purely on a structural model. While structural models do offer a way of explicitly representing behavior and agent-specific preferences that drive behavior and response, they also require that some assumptions be made by the analyst with respect to structural relationships that cannot be captured in observed data.

Another major way in which structural and reducedform approaches differ is in their ability to evaluate the counterfactual of 'no information' and its impact on farm-level agent behavior. With careful design of the sampling frame, an econometric, reduced-form approach could capture the counterfactual if there are sufficient observations of response behavior that encompass both the presence and absence of climate information. A structural approach, by contrast, would require some degree of conjecture on the part of the analyst to represent the counterfactual, given that the case with adaptation has most likely been embedded in the specification of the model.

We have pointed to some promising examples in the literature that demonstrate appropriate application of empirical methods and interesting innovations. Using these examples, we stress the importance of the improved integration of economic behavioral theory with rigorous empirical analysis, so as to take into account important rigidities, fixities or constraints that might bias the estimation of information value, when using observed behavior that is ex post of the climate outcome. Examples in the literature that have employed structural estimation techniques to characterize decision-making behavior and simulate response under climate shocks show the greatest promise of being able to capture the underlying relationships between the information the agent receives, the actions that s/he takes, and the types of constraints that s/he is facing. Other reduced form types of empirical analyses are more prone to the common criticism that they may overlook important environmental influences on the values of the behavioral parameters being measured. This, in turn, could lead to undue bias being introduced in the results, unless sufficient data and methodological expertise is available to adequately control for confounding factors that could distort the true value of information to the user. Judicious use of experimental data could possibly help alleviate these kinds of problems.

The typical scales of analysis at which these types of assessment studies are done are fairly small, being mostly confined to the farm level. A remaining challenge to researchers is to find suitable ways of scaling up from methods that rely heavily on the theory of individual decision-making under uncertainty. If we were to treat climate information as a knowledge stock that is available to a wider community of users, it might be possible to treat climate information just as another 
input to the production process, and employ those economic methods that make use of production duality, such as a profit or cost function-based approach. In this way, the econometric approach in evaluating agricultural R\&D could be adopted to evaluate climate forecast information. The constraints in this approach would be good-quality time series data. These data are currently lacking, even in developed countries such as the USA, but will be increasingly available in the future. Similar to other impact assessment studies that have evaluated knowledge stocks, researchers might also be able to evaluate spillover and distributional considerations, as related to climate information.

By pointing out the possible pitfalls and promising examples of ex post assessment, it is our hope that researchers will re-double their efforts to make the necessary improvements in survey design, data collection, and other methodological innovations that can advance both the state-of-the-art currently being applied to the study of climate forecast information, and its intrinsic value to those farmers who are most vulnerable without it. But the true benefits of improved climate forecast information can only be realized if adequate institutional support is given to make it more easily understood by the farmer and to relieve some of the institutional or structural constraints that might prevent farm-level agents from responding adequately to new information.

This suggests that the concept of agricultural extension should be expanded beyond the use of productive inputs, such as fertilizer, insecticide and seed, and should also encompass the use of information-based inputs like climate forecasts. Such information can serve to narrow the range of uncertainty facing the farm-level decision maker and to better prepare the user for more effective adaptation and response to climate-related shocks that will occur in the forecastable future.

\section{LITERATURE CITED}

Adams RM, Bryant KS, McCarl BA, Legler DM, O'Brien J, Solow A, Weiber A (1995) Value of improved long-range weather information. Contemp Econ Policy 13:10-19

Ali M, Byerlee D (1999) A decomposition analysis of productivity growth and resource degradation in Pakistan's Punjab. Policy Research Working Paper, Rural Development Department, World Bank, Washington, DC

Alston JM, Norton GW, Pardey PG (1995) Science under scarcity: principles and practices for agricultural research evaluation and priority setting. $\mathrm{CAB}$ International (CABI), Wallingford, UK

Antle JM (1996) Methodological issues in assessing potential impacts of climate change on agriculture. Agric For Meteorol 80:67-85

Antonovitz F, Roe T (1984) The value of rational expectations forecast in a risky market: a theoretical and empirical approach. Am J Agric Econ 66:717-723
Bradford DF, Kelajian HH (1978) The value of information for crop forecasting in a market system: some theoretical issues. Rev Econ Stud 44:519-531

Byerlee DR, Anderson JR (1969) Value of predictions of uncontrolled factors in response functions. Aust J Agric Econ 13:118-127

Easterling WE, Mendelsohn R (1999) Estimating the economic impacts of drought on agriculture. In Wilhite DA (ed) Drought: a global assessment-hazards and disasters: a series of definitive major works. Routledge, London, p 256-268

Fafchamps M (1993) Sequential labor decisions under uncertainty: an estimable household model of West-African farmers. Econometrica 61:1173-1197

Fox G, Turner J, Gillespie T (1999) Estimating the value of precipitation forecast information in alfalfa dry hay production in Ontario. J Prod Agric 12:551-558

Freebairn JW (1976) The value and distribution of the benefits of commodity price outlook information. Econ Rec $52: 199-212$

Freeman AM (1974) On estimating air pollution control benefits from land value studies. J Environ Econ Manag 1: $74-83$

Freeman AM (1993) The measurement of environmental and resource values. Resources for the Future Press, Washington, DC

Griliches Z (1958) Research costs and social returns: hybrid corn and related innovations. J Polit Econ 66:419-431

Hayami Y, Peterson W (1972) Social returns to public information services: statistical reporting of US farm commodities. Am Econ Rev 62:119-130

Huang J, Rozelle S (1995) Environmental stress and gain yields in China. Am J Agric Econ 77:853-864

Jochec KG, Mjelde JW, Lee AC, Conner JR (2001) Use of seasonal climate forecasts in rangeland-based livestock operations in West Texas. J Appl Meteorol 40:1629-1639

Lind RC (1973) Spatial equilibrium, the theory of rents, and the measurement of benefits from public programs. Q J Econ 87:188-207

Lindert PH (2001) Soil change in agriculture in two developing countries. In: Alston JM, Pardey PG, Taylor JT (eds) Agricultural science policy: changing global agendas. Johns Hopkins University Press and International Food Policy Research Institute, Washington, DC, p 122-160

Lucas RE (1976) Econometric policy evaluation: a critique. Carnegie-Rochester Conf Ser Publ Policy 1:19-46

Luseno WK, McPeak JG, Barrett CB, Little PD, Gebru G (2003) Assessing the value of climate forecast information for pastoralists: evidence from southern Ethiopia and Northern Kenya. World Dev 31:1477-1494

Lybbert TJ, Barrett CB, McPeak JG, Luseno WK (2003) Bayesian herders: optimistic updating of rainfall beliefs in response to external forecasts. Work Pap. Department of Applied Economics and Management, Cornell University, Ithaca, NY

Macauley MK (1997) Some dimensions of the value of weather information: general principles and a taxonomy of empirical approaches. In: Pielke RA (ed) Rep Workshop on the social and economic impacts of weather. National Center for Atmospheric Research, Boulder, CO

Maredia M, Byerlee D, Anderson JR (2000) Ex post evaluation of economic impacts of agricultural research programs: a tour of good practice. In: The future of impact assessment in the CGIAR: needs, constraints and options. CGIAR Technical Advisory Committee Secretariat, FAO, Rome

Mendelsohn R, Nordhaus W, Shaw D (1996) Climate impacts 
on aggregate farm value: accounting for adaptation. Agric For Meteorol 80:55-66

Mjelde JW, Hill S (1999) The effect of the use of improved climate forecasts on variable costs, input usage, and production. Agric Syst 60:213-225

Mjelde JW, Sonka ST, Dixon BL, Lamb PJ (1988) Valuing forecast characteristics in a dynamic agricultural production system. Am J Agric Econ 70:674-684

Mjelde JW, Hill S, Griffiths JF (1998) A review of current evidence on climate forecasts and their economic effects in agriculture. Am J Agric Econ 80:1089-1095

Pines D, Weiss Y (1976) Land improvement projects and land values. J Urban Econ 3:1-13

Polinsky AM, Shavell S (1976) Amenities and property values in a model of an urban area. J Public Econ 5:119-129

Provencher B (1997) Structural versus reduced form estimation of optimal stopping problems. Am J Agric Econ 79:357-368

Ridker RG (1967) Economic costs of air pollution: studies in measurement. Praeger, New York

Ridker RG, Henning JA (1967) The determinants of residential property values with special reference to air pollution. Rev Econ Stat 49:246-57

Rust J (1987) Optimal replacement of GMC bus engines: an

Submitted: July 19, 2005; Accepted: January 30, 2006 empirical model of Harold Zurcher. Econometrica 55: 999-1033

Schlenker W, Hanemann WM, Fisher AC (2005) Will US agriculture really benefit from global warming? Accounting for irrigation in the hedonic approach. Am Econ Rev 95:395-406

Solow AR, Adams R, Bryant K, Leger D, O'Brien J, McCarl B, Nayda W, Weiher R (1998) The value of improved ENSO prediction to US agriculture. Clim Change 39:47-60

Sonka,ST, Changnon SA, Hofing S (1988) Assessing climate information use in agribusiness II: decision experiments to estimate economic value. J Clim 1:766-774

Stern PC, Easterling WE (eds) (1999) Making climate forecasts matter. National Academy Press, Washington, DC

Stewart TR (1997) Forecast value: descriptive decision studies. In: Katz RW, Murphy AH (eds) Economic value of weather and climate forecasts. Cambridge University Press, Cambridge, p 147-181

Strotz RH (1968) The use of land value changes to measure the welfare benefits of land improvements. In: Haring JE (ed) The new economics of regulated industries. Occidental College, Los Angeles, CA

Wooldridge M (2002) Introduction to multi-agent systems. John Wiley \& Sons, New York

Proofs received from author(s): December 10, 2006 